\title{
Development of an Experimental Platform for Multi-source Complementary Heat Pump Heating System
}

\author{
Chang Liu*, Haibo Zhao, Huanwei Liu \\ School of Oceanography, Yantai University, Yantai 264005, China
}

Corresponding Author Email: liuchang0424@ 163.com

https://doi.org/10.18280/ijht.380206

Received: 8 January 2020

Accepted: 26 March 2020

\section{Keywords:}

solar energy, air-source heat pump, combined heating, experimental platform, measurement and control

\begin{abstract}
Multi-source heating technology has the characteristics of highly efficient, energy saving and environmentally friendly, it utilizes renewable energies and now it's facing important development opportunities and urgent needs. This paper designs and develops a set of multi-source complementary heat pump heating system, which takes solar energy and air energy as main sources and electric energy as auxiliary heat source, and realizes various test conditions by switching between valves, including the test on the thermal performance of solar collectors, test on the performance of heat pump unit, test on the operating parameters of solar/heat-pump combined heating system, and test on the control characteristics of heating system, etc.; a variety of terminal combinations could be selected according to the requirements of the tests. During the tests, the test data can be measured and saved in real time, the proposed experimental platform provides a high-level scientific research platform for the innovative, comprehensive, and research-based tests.
\end{abstract}

\section{INTRODUCTION}

Currently, the heating methods of buildings are mostly coalfired boilers or combined heat-and-power generation, which are one of the main factors causing air pollution in winter [1]. Solar energy and air energy have the characteristics of widely distributed, inexhaustible, and environmentally friendly, they are effective resources for sustainable and clean heating [2]. However, the energy flux density of solar energy is low and it's greatly affected by light intensity and weather conditions, and the heating capacity and performance coefficient of the air source heat pump vary greatly with the change in external ambient temperature. At the same time, due to the influence of factors such as frosting, just using one method alone can hardly meet the requirement of large-scale clean heating $[3,4]$.

In order to cope with the increasingly serious environmental pollution, governments of various countries have successively introduced a variety of policies and guidelines to vigorously promote the development and application of the clean energy industry [5]. As many countries have attached great importance to multi-energy complementary systems, it can be seen that the development prospect is very good. However, it should also be realized that different types of clean energy power generation have different characteristics. China's multienergy complementary systems are still in the initial development stage, and the understanding of multi-energy complementation is not sufficient enough $[6,7]$. There are great differences among different energy systems, generally, each kind of the energys system is planned, designed, and operated independently, and there's no coordination with each other, resulting in problems such as low energy utilization, low safety and low self-healing ability of the function systems [8]. To improve the consumption capacity of renewable energies, the complementary and optimal scheduling of multiple energy sources is one of the main methods that is technically feasible $[9,10]$.

The solar-air energy combined heating system is currently the system type that is most abundant in form and most widely researched. The solar-heated hot water + air source heat pump + passive solar house system [11] can reduce energy consumption by about $1 / 3$ and increase the comprehensive COP by about $1 / 5$. The solar-air energy combined heat-pump heating system can increase the comprehensive COP by $14 \%$ $43 \%$, the value depends on the system form and the operating environment [12-14]. The energy flux densities of renewable energy sources such as solar energy, wind energy, and geothermal energy are generally low and unstable. If they are directly connected to the heat pump system, the reliability of the system will decrease. If the energies can be concentrated and utilized, the shortcomings of the renewable energies can be weakened $[15,16]$. Compared with traditional heating methods, multi-source heating technology has the characteristics of highly efficient, energy saving and environmentally friendly, it utilizes renewable energies and now it's facing important development opportunities and urgent needs.

Science comes from practice, and most theories are obtained through experiments. A good experimental equipment is often the key to the development of a discipline, therefore in recent years, many scholars have built various related experimental platforms, such as the solar thermal collector experimental platform designed by Smyth et al. [17], the solar-assisted experimental platform proposed by Kashif et al. [18], the solar heat pump system experimental platform of Shandong University of Science and Technology [19], and the comprehensive experimental platform for air-conditioning refrigeration and heat pump teaching in Harbin Institute of Technology [20], etc. However, these experimental platforms 
can only achieve one single function, which is not conducive to innovative experimental research.

Based on an analysis of the coupling mechanism of solarair source heat pumps, this paper proposes a scheme of multisource complementary heat pump combined heating system which can provide air conditioning in summer and supply sanitary hot water throughout the year. The proposed experimental platform can not only realize the respective characteristics of solar energy heating and heat pump heating, but also achieve a few comprehensive utilization functions, which provide multiple operation modes for subsequent tests. This experimental platform fully shows the novel system form of comprehensively applying solar energy and air energy to the heating systems and its monitoring method, and it can promote the experimental teaching and research works of college disciplines such as energy and power related majors and the building environment and equipment engineering major in terms of solar-air energy heat pump, clean heating technologies, and other aspects.

\section{PRINCIPLE AND OPERATING LOGIC OF THE EXPERIMENTAL PLATFORM}

\subsection{Principle of the experimental platform}

The proposed experimental platform consists of a measuring chamber, a solar collector, an air source heat pump, a hot water storage tank, and an indoor heating device, etc. The solar heat collection system was used to absorb solar radiation and convert it into heat energy; the air source heat pump was used to extract heat from the air outside, raise its temperature, and transport it indoors to achieve the purpose of heating; in case of extreme weather, the electric heater can be used to assist heating when the heat supply is insufficient.

The system principle is shown in Figure 1. The solar-air heat pump is the main part that can realize clean and efficient heating in winter, cooling in summer, and supply sanitary hot water throughout the year.

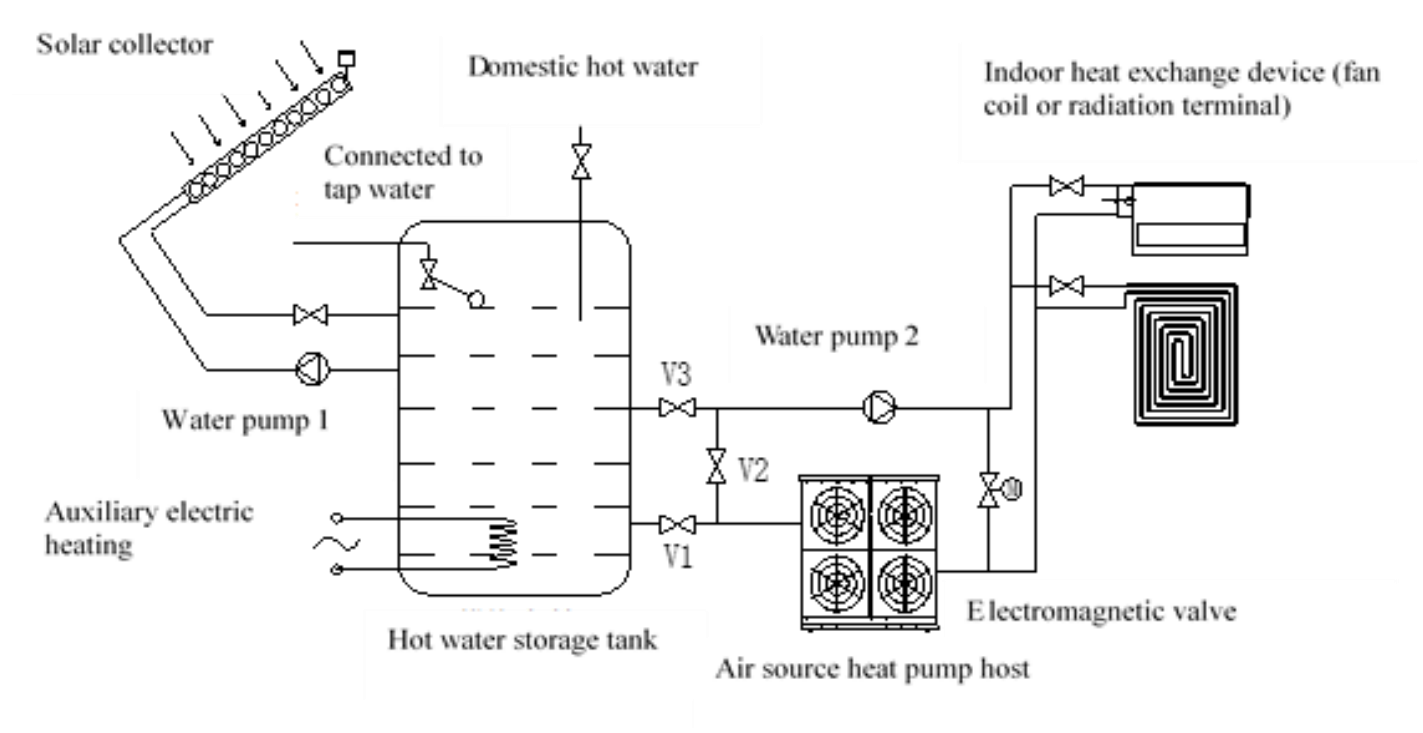

Figure 1. System principle

\subsection{Realizable operating logic of the experimental platform}

For the cold northern regions, during the entire heating season, the air source heat pumps can operate efficiently most of the time [21], so they should be the first choice. However, under harsh weather conditions, only using air source heat pumps alone cannot meet the load requirement of the buildings, solar heat collection system could be integrated to form an air source heat pump and solar energy complementary heating system.

The system has two operating modes: the winter mode and the summer mode, which can offer heating, cooling, and water supply functions respectively, as shown in Figure 1.

When heating in winter, close valve V2 and open valves V1 and V3. In the daytime, solar energy is used first. The solar collecting plates collect solar energy to heat the water in the hot water storage tank, at this time, the heat pump does not work; if the heating requirement cannot be met, then turn on the air-source heat pump to continue to increase the temperature of the water in the water tank; under extreme conditions, turn on the auxiliary electric heating. At night, air source heat pump is used for heating.

When cooling in summer, close valves V1 and V3 and open valve V2. The system can be divided into two separate parts, the air source heat pump is used to cool the building, and solar energy + hot water storage tank could provide domestic hot water.

In areas with time-of-use electricity prices, the peak-valley electricity price policy can be combined to make use of the valley-price electricity for heating to reduce the operating costs; at night, the heat-and-store mode of the air source heat pumps could be turned on.

(1) When the nighttime outdoor ambient temperature is suitable, the air source heat pumps supply heat to the building, meanwhile store heat to the hot water storage tank;

(2) When the nighttime outdoor ambient temperature is low, the air source heat pumps supply heat to the building, and auxiliary electric heating could be turned on;

(3) When nighttime outdoor environment is harsh, and the air source heat pumps cannot meet the heating requirement, the auxiliary electric heating could be turned on;

(4) In daytime, the hot water and solar energy are firstly used to supply heat to the building, if the heating requirement cannot be met, then the air source heat pumps could be turned on, still, under extreme conditions, auxiliary electric heating could be turned on as well. 


\section{COMPOSITION OF EXPERIMENTAL PLATFORM AND TEST ITEMS}

This experimental platform is an experiment chamber in the lab, in earlier time, the chamber had been equipped with a cold storage system, as shown in Figure 2. The cold storage system can provide a maximum of $30 \mathrm{KW}$ cooling capacity, so the load of the building can be adjusted as needed to realize dynamic matching of the heating system and the heating load of the building.

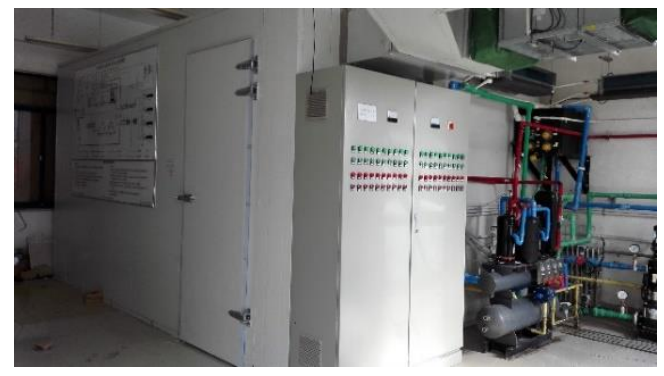

Figure 2. Experiment chamber

\subsection{Composition of the experiment platform system}

Based on the analysis of the coupling mechanism of the solar-air source heat pump, a prototype was fabricated. The main components are shown in Figure 3.

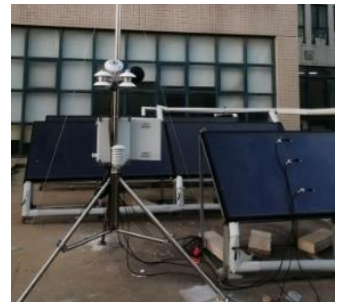

(a) Solar collector system

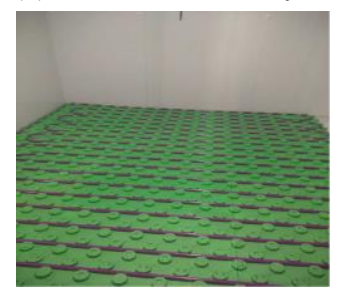

(c) Radiation terminal

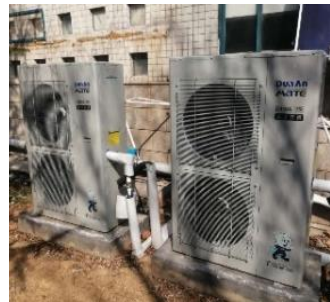

(b) Heat pump unit

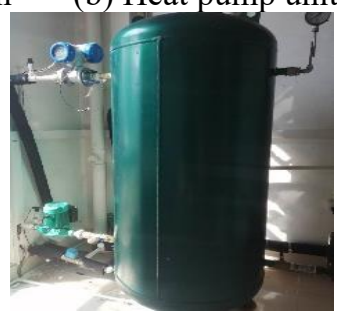

(d) Hot water storage tank
Figure 3. Main components of the system

\subsubsection{Solar collector system}

Five $2000 \mathrm{~mm} \times 1000 \mathrm{~mm}$ solar collecting plates were arranged horizontally at a spacing distance of $500 \mathrm{~mm}$, all plates were toward the south, and the thermal efficiency was $55 \%$. On sunny and cloudless days, it could produce $55^{\circ} \mathrm{C}$ hot water with a water volume between 75 and $140 \mathrm{~kg} / \mathrm{m}^{2}$. The solar heat collection system works best on sunny and cloudless days, the cold water entering the heat collector from the bottom is heated by the solar energy in the fluid channel, its temperature is raised gradually, the heated hot water carrying useful heat flows out from the top outlet of the heat collector, and is stored in the water tank for later use.

\subsubsection{Air source heat pump system}

Two air-source pump hot/cold water units were integrated to operate in parallel, each with a heating capacity of $10 \mathrm{KW}$, when the outdoor temperature is $-25^{\circ} \mathrm{C}$ or above, they can operate stably and produce hot water above $65^{\circ} \mathrm{C}$, and both have the automatic defrosting function.

\subsubsection{Hot water storage tank}

The water tank is a container used for storing hot water in the proposed system, it is a cylindrical heat preservation pressurized water tank, the inner tank was made of 304 stainless steel, the insulation layer was made of $5 \mathrm{~cm}$ polyurethane foam, the outer tank was made of 201 stainless steel. The diameter of the water tank is $0.9 \mathrm{~m}$, the height is $1.4 \mathrm{~m}$, and the weight is about 2.1 tons, its pressure bearing capacity is $0.5 \mathrm{MPa}$.

\subsubsection{Terminal system}

The terminal system adopted two kinds: one system was a radiation heating system that was set on the indoor floor surface, the material of the radiation floor was cross-linked polyethylene, the spacing of the floor heating pipes was $100 \mathrm{~mm}-350 \mathrm{~mm}$, and the heat preservation material was $15 \mathrm{~mm}-30 \mathrm{~mm}$ composite polystyrene boards. The radiation method has the advantages of uniform temperature distribution, occupying no room space, healthy and comfortable, etc.; in addition, the floor radiation heating system adopted lowtemperature hot water for heating, which can effectively make use of the low-grade heat sources, and have obvious energysaving effects [22]; the other system was the fan coil system that was hung on the indoor wall surface, it achieved the purpose of heating through heat exchange between hot water and indoor air, and the heat exchange power was $10 \mathrm{KW}$.

\subsection{Achievable test items of the experimental platform}

Through the switching of different valves, the experimental platform can test on the separate operation of solar collection system, the separate operation of air source heat pump system, and the operation of air source heat pump assisted by solar energy; combined with data monitoring and collection systems, the platform can carry out various tests, such as the test on thermal performance of solar collector, test on performance of heat pump unit, test on operating parameters of solar/heatpump combined heating system, test on energy efficiency of various heating (cooling) terminals, and test on the control characteristics of heating system, etc.

Test on the thermal performance of solar collector. The achievable test items include: the change laws of heat collecting capacity with season, climate, time period, installation angle, etc.; the change laws of heat collecting efficiency with water temperature, environmental temperature and other parameters; and the changes in heat collection and heat dissipation, etc.

Test on the performance of heat pump unit. The achievable test items include: cooling capacity, heating capacity, input power, condensation temperature, evaporation temperature, compressor discharge temperature, evaporation pressure, condensation pressure, refrigerant flow and other parameters under different working conditions.

Test on the operating parameters of solar-heat pump heating system. The achievable test items include: off-design operating characteristics of the heating system; the influence of the heat source side water volume, the user side water volume and the water temperature on the heating system; system energy consumption; and the system optimization design strategies, etc. 
Test on the energy efficiency of various heating (cooling) terminals. The achievable test items include: the influence of different terminal forms on indoor temperature, humidity and overall comfort level; and the system energy efficiency under different terminals or terminal combinations.

Test on the control characteristics of heating system. The achievable test items include: thermal response performance, solar-heat pump coupling performance, control strategies and optimization, and control system performance, etc.

\section{EXPERIMENTAL PLATFORM COLLECTION AND TEST SOFTWARE}

\subsection{Hardware of the test system}

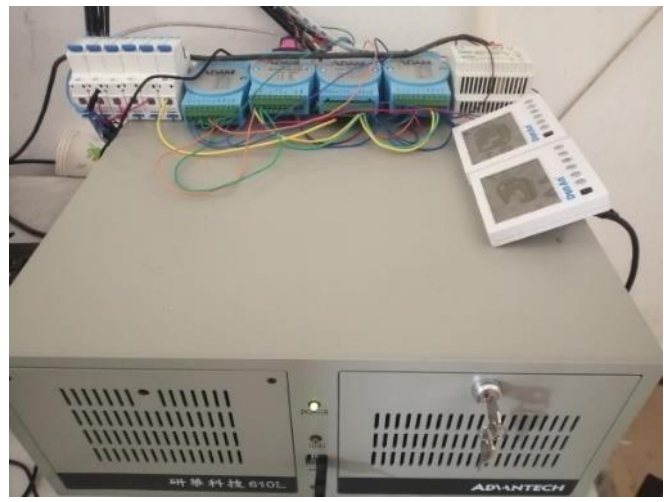

Figure 4. Test hardware
Hardware is the foundation of the entire test system. The upper computer of the experiment platform was the IPC-610L (Industrial Personal Computer) produced by Taiwan Advantech, the data collection equipment was the ADAM4000 series modules produced by Taiwan Advantech, as shown in Figure 4. As the core part of the performance test system, ADAM-4000 series modules can use advanced programming languages that support ASCII string functions, such as VC and VB, to write module applications, and they also support some graphical tools [23]. This paper adopted LabVIEW to construct the system and realize data collection and control of the system.

\subsection{Data collection}

According to the requirement of the experiment, the data collection system of the proposed experimental platform mainly collects and measures the temperature and humidity of the measuring chamber, the temperature of the hot water storage tank, and the temperature, flow, pressure and differential pressure of each pipeline of the supply and return water, etc. All data can be transmitted remotely. The host computer adopted the MSCOMM serial communication control provided by VB6.0, and at the same time, the use convenience and safety of users were taken into consideration, and the software was programmed according to the corresponding communication protocol to realize data exchange with data collection system on the site. The layout of the measuring points of the experiment is shown in Figure 5 .

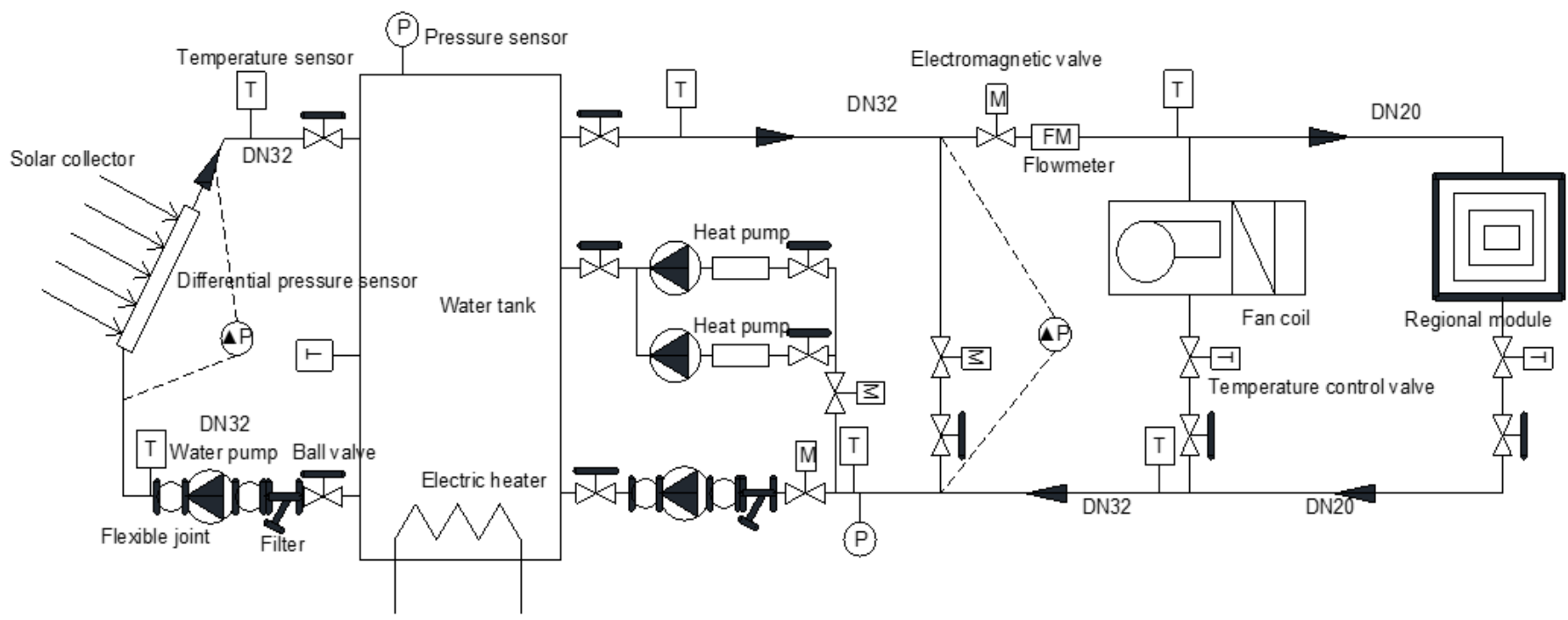

Figure 5. Experimental system and measuring point layout

\subsubsection{Collection of temperature and humidity}

The experimental platform adopted the Pt1000 temperature sensor to measure the temperature and humidity of the measuring chamber, the temperature of the inlet and outlet of the solar collection system, the temperature of the hot water storage tank, and the surface temperature of the radiation floor. In addition, the TFSS1000 online micro-environment measurement system was adopted to measure the outdoor environment temperature and humidity, the surface temperature of the solar collector and the total solar radiation intensity. In the tests, a temperature sensor was arranged at the high, middle and low positions of the solar collector each.

\subsubsection{Collection of flow}

According to the requirement of the experimental platform, two electromagnetic flowmeters were set to measure the water flow of the solar collector and the main water supply pipeline, combined with the temperature collection of the supply and return water, the heating capacity of the solar collector, the heating/cooling capacity of the heat pump unit and the heating/cooling capacity of the terminals of the air-condition chamber could be calculated.

4.2.3 Collection of pressure and differential pressure

Differential pressure sensors were arranged respectively on 
the solar collection system and on the main pipeline of supply and return water to monitor the operating pressure of the system, so as to ensure the normal operation of the system.
The main sensor performance parameters are shown in Table 1.

Table 1. Main sensor performance parameters

\begin{tabular}{cccc}
\hline Name & Measuring range & Output signal & Accuracy \\
\hline Electromagnetic flowmeter & $0.5 \mathrm{~m} / \mathrm{s}-10 \mathrm{~m} / \mathrm{s}$ & Pulse output & $\leq \pm 0.3 \%$ \\
Pressure transmitter & $0-100 \mathrm{MPa}$ & $4-20 \mathrm{mADC}$ & $\pm 0.5 \% \mathrm{FS}$ \\
Differential pressure sensor & $0-100 \mathrm{MPa}$ & $4-20 \mathrm{mADC}$ & $\pm 0.5 \% \mathrm{FS}$ \\
Temperature sensor & $-50-500^{\circ} \mathrm{C}$ & Resistance signal & $\pm 0.1^{\circ} \mathrm{C}$ \\
\hline
\end{tabular}

\subsection{Test software function}

By switching control buttons, the host computer test software could display different real-time data collection interfaces, including the data of solar collector in winter, the data of air source heat pumps, the data of floor radiation temperature, and the data of temperature and humidity of the chamber, etc.; moreover, the software can also store the realtime data, save the collected data to the corresponding database and conduct analysis.

The system performance test software was developed using the graphical programming language LabVIEW, which mainly includes the following functional modules:

System test. The main function of this module is to automatically monitor whether the communication between the IPC and each ADAM data collection module is normal when the program is initiated. Only when the communication is normal, can the IPC communicate with the modules and perform corresponding operations.

Real-time display. As shown in Figure 6, the simulated working condition diagram can display the simulated operation status of the entire system and the measured value of each point in real time.

Printing function. Curve printing: print parameter curves; report printing: print the actual test results in the form of EXCEL reports, and create test reports and data record tables.

Debugging function. Display the analog quantities, physical quantities, coefficients and deviations of each sensor, the coefficients and deviations could be configured to realize the calibration of the physical quantities.

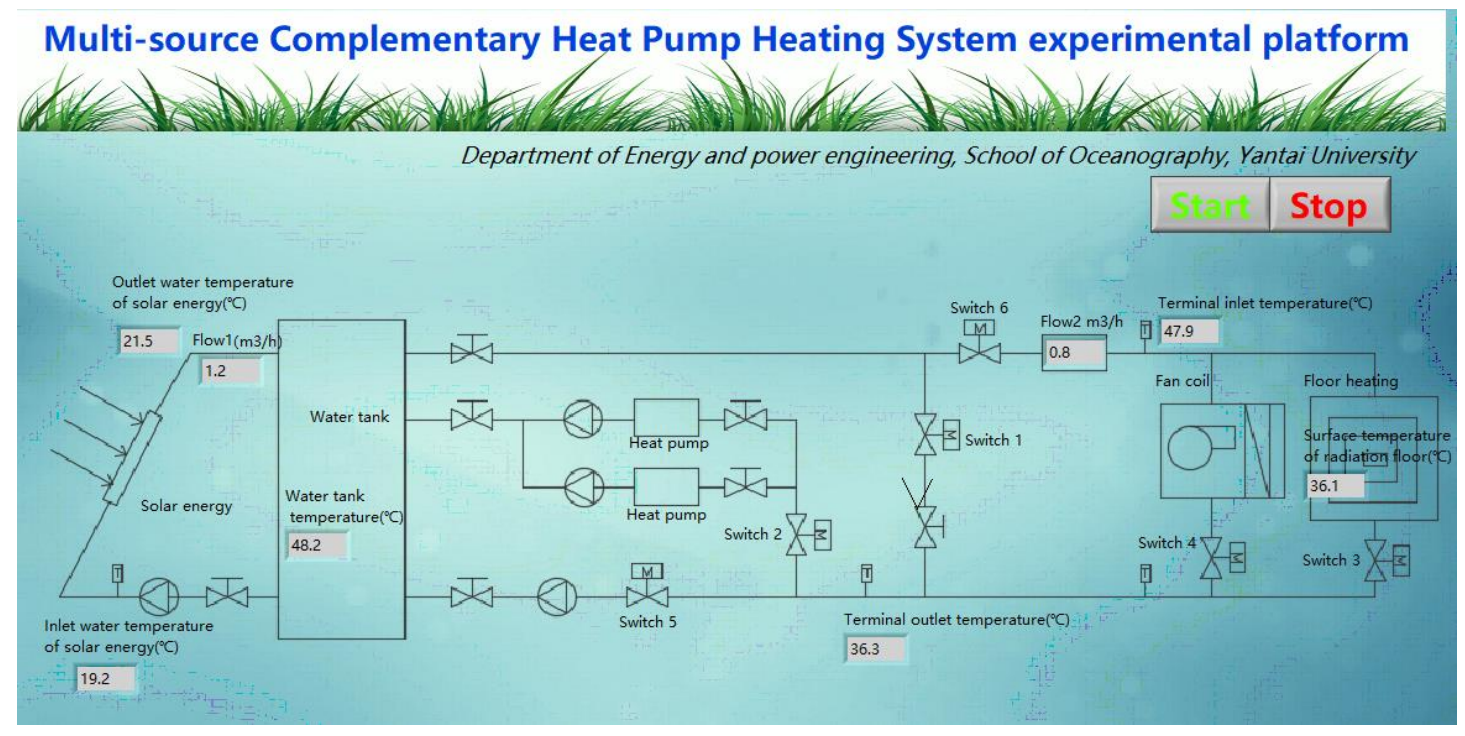

Figure 6. Test software interface

\section{CONCLUSION}

This study constructed an experimental platform for the multi-source complementary heat pump heating system, and completed works such as process design, equipment selection, and data collection, etc. The proposed platform integrated solar energy and air source heat pumps to realize the complementation and synergy of solar energy and air source heat pumps, it could carry out research on the energy efficiency of heating/cooling operations and the indoor terminal system, etc. The experimental platform has a high degree of automation, and high accuracy and reliability; it could provide good teaching demonstrations and comprehensive experimental content; moreover, the platform not only provides a high-level research platform for the cultivation of undergraduates and scientific research, but also offers an efficient and energy-saving test device for the inspection of solar energy devices, air source heat pumps and other related products, thereby truly realizing the integrated functions of teaching, scientific research and services.

\section{REFERENCES}

[1] Xu, J.J., Kang, H., Zhang, R.H. (2019). Clean coal-fired heating and comprehensive utilization of energy. Huadian Technology, 41(11): 36-39.

[2] 2018 Global Renewable Energy Status Report, REN21, 2019. http://www.solarpwr.cn/bencandy-52-37551.html.

[3] Yu, B.Q. (2012). Research on adaptability of multi-heat 
source heat pump system in hot summer and warm winter area. Guangxi University, 2012.

[4] Banister, C.J., Collins, M.R. (2015). Development and performance of a dual tank solar-assisted heat pump system. Applied Energy, 149: 125-132. https://doi.org/10.1016/j.apenergy.2015.03.130

[5] Nei, H.N., Huang, X.L., Zeng, Z.Y. (2018). Present Situation and Development Prospect of Clean Energy Heating in China. Energy and Energy Conservation, 2018(12): 87-89. https://doi.org/10.16643/j.cnki.141360/td.2018.12.035

[6] Suškevičs, M., Eiter, S., Martinat, S., Stober, D., Vollmer, E., de Boer, C.L., Buchecker, M. (2019). Regional variation in public acceptance of wind energy development in Europe: What are the roles of planning procedures and participation. Land Use Policy, 81: 311323. https://doi.org/10.1016/j.landusepol.2018.10.032

[7] Lu, S., Gu, W., Zhou, J., Zhang, X., Wu, C. (2018). Coordinated dispatch of multi-energy system with district heating network: Modeling and Solution Strategy. Energy, 152: 358-370. https://doi.org/10.1016/j.energy.2018.03.088

[8] Acharya, S., El Moursi, M.S., Al-Hinai, A. (2017). Coordinated frequency control strategy for an islanded microgrid with demand side management capability. IEEE Transactions on Energy Conversion, 33(2): 639651. https://doi.org/10.1109/TEC.2017.2763186

[9] Banshwar, A., Sharma, N.K., Sood, Y.R., Shrivastava, R. (2019). Market-based participation of energy storage scheme to support renewable energy sources for the procurement of energy and spinning reserve. Renewable Energy, 135: 326-344. https://doi.org/10.1016/j.renene.2018.12.009

[10] Baruah, D.C., Enweremadu, C.C. (2019). Prospects of decentralized renewable energy to improve energy access: A resource-inventory-based analysis of South Africa. Renewable and Sustainable Energy Reviews, 103: 328-341. https://doi.org/10.1016/j.rser.2019.01.006

[11] Shan, M., Yu, T.H., Yang, X. (2016). Assessment of an integrated active solar and air-source heat pump water heating system operated within a passive house in a cold climate zone. Renewable Energy, 87: 1059-1066. https://doi.org/10.1016/j.renene.2015.09.024

[12] Poppi, S., Bales, C., Heinz, A., Hengel, F., Chèze, D., Mojic, I., Cialani, C. (2016). Analysis of system improvements in solar thermal and air source heat pump combisystems. Applied Energy, 173: 606-623. https://doi.org/10.1016/j.apenergy.2016.04.048

[13] Lerch, W., Heinz, A., Heimrath, R. (2015). Direct use of solar energy as heat source for a heat pump in comparison to a conventional parallel solar air heat pump system. Energy and Buildings, 100: 34-42. https://doi.org/10.1016/j.enbuild.2015.03.006
[14] Deng, W., Yu, J. (2016). Simulation analysis on dynamic performance of a combined solar/air dual source heat pump water heater. Energy Conversion and Management, 120: 378-387. https://doi.org/10.1016/j.enconman.2016.04.102

[15] Yang, L., Tai, N., Fan, C., Meng, Y. (2016). Energy regulating and fluctuation stabilizing by air source heat pump and battery energy storage system in microgrid. Renewable Energy, 95: 202-212. https://doi.org/10.1016/j.renene.2016.04.019

[16] Jabari, F., Nojavan, S., Ivatloo, B.M. (2016). Designing and optimizing a novel advanced adiabatic compressed air energy storage and air source heat pump based $\mu$ Combined Cooling, heating and power system. Energy, 116:

64-77. https://doi.org/10.1016/j.energy.2016.09.106

[17] Smyth, M., Barone, G., Buonomano, A., Forzano, C., Giuzio, G.F., Palombo, A., McLarnon, D. (2020). Modelling and experimental evaluation of an innovative Integrated Collector Storage Solar Water Heating (ICSSWH) prototype. Renewable Energy, 157: 974-986. https://doi.org/10.1016/j.renene.2020.05.074

[18] Kashif, A., Ali, M., Sheikh, N.A., Vukovic, V., Shehryar, M. (2020). Experimental analysis of a solar assisted desiccant-based space heating and humidification system for cold and dry climates. Applied Thermal Engineering, 175:

115371 . https://doi.org/10.1016/j.applthermaleng.2020.115371

[19] Kong, X.Q., Li, Y., Yang, Q.M. (2010). Development of Solar Assisted Heat Pump System Integrated Experimental Platform. Research and Exploration in Laboratory, 29(6): 18-20. https://doi.org/10.3969/j.issn.1006-7167.2010.06.006

[20] Zhao, Y.L. (2009). Development of a comprehensive experimental platform for air conditioning, refrigeration and heat pump teaching. Harbin Institute of Technology. https://doi.org 10.7666/d.D270543

[21] Liu, H., Jiang, Y., Yao, Y. (2014). The field test and optimization of a solar assisted heat pump system for space heating in extremely cold area. Sustainable Cities and Society, 13: 97-104. https://doi.org/10.1016/j.scs.2014.05.002

[22] Baek, S., Kim, S. (2018). Determination of optimum hotwater temperatures for PCM radiant floor-heating systems based on the wet construction method. Sustainability, 10(11): 4004. https://doi.org/10.3390/su10114004

[23] Zhao, Y.J., Lou, C.Z., An, N. (2015). Development of integrated experiment platform for solar/geothermal energy/heat pump system. Acta Energiae Solaris Sinica, 36(6): 1306-1311. https://doi.org/10.3969/j.issn.02540096.2015.06.004 